\title{
Compósito madeira-plástico a partir de resíduos de três espécies florestais
}

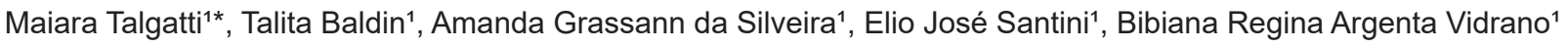 \\ ${ }^{1}$ Universidade Federal de Santa Maria, Av. Roraima, 1000, Camobi, CEP 97105-900, Santa Maria, RS, Brasil
}

*Autor correspondente:
maiara.talgatti@hotmail.com

Termos para indexação:

Resíduos de madeira

Micrografia de varredura

Termoplástico

Index terms:

Wood residues

Scanning microscopy

Thermoplastic

Recebido em 22/11/2016

Aprovado em 10/09/2017

Publicado em 29/09/2017

doi: 10.4336/2017.pfb.37.91.1385

\begin{abstract}
Resumo - O presente estudo teve por objetivo avaliar as propriedades físicas e mecânicas de compósitos madeira-plástico, utilizando materiais de baixo nível de processamento. Para tal, utilizou-se madeira proveniente de resíduos de marcenaria, na forma de maravalha, de três espécies florestais (Pinus elliottii, Hovenia dulcis e Maclura tinctoria), e termoplástico do tipoßpoliestireno. Os dados foram submetidos ao teste de Duncan a 95\% de confiabilidade. Para os ensaios mecânicos de módulo de ruptura (MOR) e módulo de elasticidade (MOE) todos os tratamentos apresentaram bons resultados, não se diferenciando entre si. Os ensaios de ligação interna e arrancamento do parafuso não apresentaram resultados satisfatórios, sendo que para este último o melhor resultado foi verificado para Hovenia dulcis. Quanto ao inchamento em $2 \mathrm{~h}$ e 24 $\mathrm{h}$, todos os tratamentos mostram resultados positivos. De maneira geral, os resultados não foram influenciados pelas espécies utilizadas.
\end{abstract}

\section{Wood-plastic composites from residues of three forest species}

\section{Introdução}

A busca por soluções que determinem o emprego e produção de novos materiais com base na utilização de resíduos é tendência do mercado. Obter produtos ecologicamente corretos reduz custos com descarte e aumenta os lucros à medida que o resíduo se torna um produto comercial para as indústrias. A diversificação das bases para a fabricação de compósitos reconstruídos, por meio de novos produtos, poderá beneficiar o setor florestal, ao passo que a fabricação industrial poderá aumentar, sem que haja necessariamente a implantação de novos maciços florestais. Seguindo esta tendência, a reutilização de resíduos provenientes de outros setores da indústria, como o caso dos rejeitos plásticos, valoriza 
o trabalho dos recicladores, agregando maior valor ao mesmo, além de abrir um leque de futuras utilizações destes materiais. Do mesmo modo, de acordo com a Associação Brasileira de Produtores de Florestas Plantadas (Anuário..., 2013), a utilização dos resíduos madeireiros, como o caso da maravalha, possibilita o aumento do rendimento industrial e reduz os seus impactos ambientais.

Os compósitos termoplásticos, ou compósitos madeira-plástico (CMP), são produtos obtidos a partir de uma matriz de resina termoplástica reforçada com partículas de madeira, combinando as melhores qualidades de cada constituinte (Maciel et al., 2004). Para Yamaji \& Bonduelle (2004), os compósitos de madeira e plástico possuem como vantagens em relação aos convencionais a baixa densidade, o baixo custo, a alta resistência específica e o alto módulo de elasticidade.

A fabricação de compósitos utilizando farinha ou fibra de madeira como carga em termoplásticos é conhecida, conforme relatos de Correa et al. (2003), desde 1970 pela indústria automobilística, que emprega compósitos de polipropileno com farinha de madeira. Porém, sua ampla utilização nas demais indústrias ainda é pouco empregada.

Tendo em vista o exposto, este trabalho teve como objetivo avaliar a qualidade de compósitos madeiraplástico produzidos com resíduos disponíveis na serraria local, de três espécies florestais (Pinus elliottii Engelm., Hovenia dulcis Thunb. E Maclura tinctoria (L.) D. Don. ex Steud.), associados ao plástico do tipo poliestireno, com base nos resultados de suas propriedades físicas e mecânicas.

\section{Material e métodos}

Para produção dos compósitos de madeira-plástico (CMP) foram utilizados resíduos de desdobro, conhecidos como maravalha, das espécies florestais: Pinus elliottii Engelm., Hovenia dulcis Thunb. E Maclura tinctoria (L.) D. Don. ex Steud., provenientes da serraria do Laboratório de Produtos Florestais localizado sob as coordenadas $29^{\circ} 43^{\prime} 04^{\prime}$ 'S e $53^{\circ} 43^{\prime} 35^{\prime}$ 'W. As partículas de plástico do tipo poliestireno (PS), foram obtidas por meio do processamento de copos plásticos em moinho de martelos, equipado com peneira de malha de $5 \mathrm{~mm}$. Para uniformizar as partículas de poliestireno e maravalha, os resíduos de serraria também foram processados em moinho de martelos com peneira de $5 \mathrm{~mm}$.
As chapas de CMP foram produzidas com proporções de maravalha e poliestireno em $50 \%$. A formulação com cada uma das três espécies florestais foi considerada um tratamento, sendo produzidos dois compósitos por tratamento. Para a confecção dos compósitos, a maravalha foi seca em estufa laboratorial na temperatura de $100 \pm 3{ }^{\circ} \mathrm{C}$ até que atingisse $3 \%$ de umidade. Para a determinação da geometria das partículas, foram selecionadas, aleatoriamente, 100 amostras de maravalha de cada espécie e de poliestireno e determinados os parâmetros de comprimento, largura e espessura. Para a determinação da massa específica a granel, foi utilizado um béquer tarado e com dimensões conhecidas, onde as partículas de maravalha e de poliestireno foram acondicionadas, sem esforço físico, sendo determinada sua massa.

Após, as partículas de madeira, poliestireno e o agente de acoplamento anidrido maleico, foram pesados em balança digital para formar o colchão em camadas, sendo quatro camadas de poliestireno, três de madeira e seis de anidrido maleico. A função do anidrido maleico é compatibilizar o termoplástico com carga vegetal, promovendo uma boa adesividade interfacial entre as fibras e a matriz. Todos os compósitos foram produzidos sem a utilização de adesivo. Para a determinação fiducial da geometria das partículas, foram selecionadas, aleatoriamente, 100 amostras, sendo determinado comprimento, largura e espessura. O índice de esbeltez foi calculado pela relação entre o comprimento e espessura das partículas e a razão de planicidade calculada pela relação entre a largura e espessura.

Para a produção dos compósitos, foram utilizados os seguintes parâmetros: pressão de prensagem de 127 $\mathrm{kgf} \mathrm{cm}^{-2}$; temperatura dos pratos na chapa aquecedora de $110^{\circ} \mathrm{C}$; tempo de prensagem de 15 min e tempo de fechamento da prensa de $40 \mathrm{~s}$. O colchão foi formado manualmente, em uma caixa de madeira com dimensões de $40 \mathrm{~cm}$ x $40 \mathrm{~cm}$ x $20 \mathrm{~cm}$, e pré-prensado em prensa manual à temperatura ambiente por, aproximadamente, 1 min. Após pré-prensagem a frio, o colchão de partículas foi retirado da caixa formadora e levado à prensa hidráulica.

Após prensagem a quente, os compósitos foram identificados para confecção dos corpos de prova, de acordo com as normas para cada teste. Esses permaneceram acondicionados em câmara climatizada com temperatura de $20^{\circ} \mathrm{C}$ e $65 \%$ de umidade relativa do ar, até atingirem peso constante. A avaliação da qualidade 
das chapas produzidas compreendeu a determinação das propriedades físicas: teor de umidade; massa específica; absorção de água e inchamento em espessura, após $2 \mathrm{~h}$ e $24 \mathrm{~h}$ de imersão, e das propriedades mecânicas: flexão estática; arrancamento de parafuso e dureza de Janka, adotando as recomendações da norma ASTM D 1037 (American Society for Testing Materials, 1993).

Para a visualização dos espaços vazios e interação cola-partícula, utilizou-se a microscopia eletrônica de varredura (M.E.V. marca TESCAN VEGA3). Para tanto, as amostras cilíndricas de $12 \mathrm{~mm}$ de diâmetro foram fraturadas manualmente e recobertas por uma fina camada de ouro.

Os dados das propriedades físico-mecânicas foram avaliados por meio de delineamento inteiramente casualizado com três tratamentos e três repetições. Havendo a rejeição de hipótese de igualdade, foi aplicado o teste de Duncan para comparação das médias entre os tratamentos.

\section{Resultados}

\section{Geometria das partículas}

Os resultados das características dimensionais e geometria das partículas de Pinus elliottii, Hovenia dulcis e Maclura tinctoria estão apresentados na Tabela 1. Em geral, as características dimensionais das partículas diferem. Porém, quando se observa o volume, verifica-se que $P$. elliottii e $H$. dulcis não apresentam diferenças. Apenas M. tinctoria diferencia-se das demais partículas, com volume menor. A análise do índice de esbeltez mostra que as partículas de pinus apresentam maior valor. Por serem longas, resultam em uma maior área de contato e consumo de adesivo, seguido de $H$. dulcis e poliestireno, com valores semelhantes, e $M$. tinctoria com o menor índice.

Quanto à planicidade, verificaram-se maiores valores para $P$. elliottii e $H$. dulcis, que não diferiram entre si. Para a massa específica a granel foram observados maiores valores para $M$. tinctoria e $P$. elliottii, que não diferindo entre si.

Tabela 1. Valores médios das características dimensionais, massa específica a granel (MeG), índice de esbeltez (Iez) e razão de planicidade $(\mathrm{Rp})$ das partículas de três espécies florestais e poliestireno.

\begin{tabular}{cccccccc}
\hline Tratamento & $\begin{array}{c}\text { Comprimento } \\
(\mathbf{c m})\end{array}$ & $\begin{array}{c}\text { Espessura } \\
(\mathbf{m m})\end{array}$ & $\begin{array}{c}\text { Largura } \\
(\mathbf{m m})\end{array}$ & $\begin{array}{c}\text { Volume } \\
\left(\mathbf{m m}^{3}\right)\end{array}$ & Iez & Rp & $\begin{array}{c}\text { MeG } \\
\left(\mathbf{g ~ c m} \mathbf{~ c m}^{-3}\right)\end{array}$ \\
\hline Pinus elliottii & $9,14 \mathrm{ab}(12,01)$ & $0,52 \mathrm{a}(7)$ & $3,54 \mathrm{a}(3,89)$ & $14,16 \mathrm{a}(6,55)$ & $4,81 \mathrm{a}(3,66)$ & $1,58 \mathrm{a}(5,25)$ & $0,13 \mathrm{a}(3,25)$ \\
Hovenia dulcis & $11,40 \mathrm{a}(11,05)$ & $0,40 \mathrm{ab}(6,95)$ & $3,87 \mathrm{a}(4,03)$ & $15,25 \mathrm{a}(9,36)$ & $4,01 \mathrm{ab}(6,53)$ & $1,49 \mathrm{a}(7,01)$ & $0,10 \mathrm{~b}(2,95)$ \\
Maclura tinctoria & $8,18 \mathrm{~b}(13)$ & $0,37 \mathrm{~b}(8,56)$ & $2,87 \mathrm{~b}(4,86)$ & $9,27 \mathrm{~b}(4,08)$ & $3,17 \mathrm{~b}(5,32)$ & $1,10 \mathrm{~b}(5,78)$ & $0,14 \mathrm{a}(4,75)$ \\
\hline
\end{tabular}

* Médias seguidas pela mesma letra, na coluna, não diferem entre si pelo teste de Duncan à $5 \%$ de probabilidade. Coeficiente de variação apresentado entre parênteses (\%).

\section{Propriedade físicas}

Na tabela 2 observam-se os valores médios resultantes dos ensaios físicos de densidade, teor de umidade, absorção e inchamento em água. Os valores de densidade básica dos compósitos plástico-madeira para as três espécies de maravalha, foram semelhantes, variando entre $0,75 \mathrm{~g} \mathrm{~cm}^{-3} \mathrm{e} 0,86 \mathrm{~g} \mathrm{~cm}^{-3}$.

Tabela 2. Propriedade físicas dos compósitos madeira-plástico.

\begin{tabular}{cccc}
\hline \multirow{2}{*}{ Propriedades físicas dos compósitos } & \multicolumn{3}{c}{ Tratamentos } \\
\cline { 2 - 4 } & Pinus elliottii & Hovenia dulcis & Maclura tinctoria \\
\hline Densidade $\left(\mathrm{g} \mathrm{cm}^{-3}\right)$ & $0,86 \mathrm{a}(3,26)$ & $0,75 \mathrm{a}(2,91)$ & $0,83 \mathrm{a}(3,36)$ \\
Teor de umidade (\%) & $3,21 \mathrm{a}(5,02)$ & $3,07 \mathrm{a}(8,76)$ & $3,86 \mathrm{a}(5,41)$ \\
Inchamento em espessura 2 h (\%) & $6,55 \mathrm{a}(12,27)$ & $2,75 \mathrm{~b}(10,33)$ & $2,55 \mathrm{~b}(10,76)$ \\
Inchamento em espessura 24 h (\%) & $7,91 \mathrm{a}(7,85)$ & $5,03 \mathrm{ab}(6,23)$ & $3,38 \mathrm{~b}(7,03)$ \\
Absorção de água 2 h (\%) & $15,03 \mathrm{a}(10,02)$ & $10,81 \mathrm{a}(8,05)$ & $13,17 \mathrm{a}(8,79)$ \\
Absorção de água 24 h (\%) & $21,62 \mathrm{a} \mathrm{(12)}$ & $16,70 \mathrm{a}(11,22)$ & $16,68 \mathrm{a}(8,79)$ \\
\hline
\end{tabular}

*Médias seguidas pela mesma letra, na linha, não diferem entre si pelo teste de Duncan a $5 \%$ de probabilidade. Coeficiente de variação apresentado entre parênteses (\%). 
Quanto ao teor de umidade dos painéis, não foram observadas diferenças estatísticas. Todos os tratamentos apresentaram teores de umidade inferiores aos da madeira sólida para as mesmas condições de climatização $\left(25^{\circ} \mathrm{C}\right.$ e $\left.\mathrm{TU}=65 \%\right)$. O inchamento em espessura é uma importante propriedade que representa a estabilidade de um painel. Sendo assim, os compósitos estudados em todos os tratamentos e em $2 \mathrm{~h}$ e $24 \mathrm{~h}$ de ensaio, apresentaram comportamentos semelhantes.

Quanto à absorção de água pelos compósitos termoplásticos, tanto em $2 \mathrm{~h}$ de exposição à água quanto em 24 h, não foi verificada diferença estatística entre os tratamentos. Em todos os casos, a absorção de água aumentou com o aumento do tempo de imersão.

\section{Propriedades mecânicas}

Na Tabela 3 pode-se observar o desempenho em propriedades mecânicas entre os tratamentos avaliados. Não houve diferenciação entre os tratamentos nos ensaios de resistência a tração, módulos de ruptura (MOR) e de elasticidade (MOE). No entanto, no ensaio de arrancamento do parafuso houve diferença estatística entre as espécies, sendo o maior valor verificado para H. dulcis.

Tabela 3. Propriedade mecânicas dos compósitos madeira-plástico.

\begin{tabular}{cccc}
\hline \multirow{2}{*}{ Propriedades mecânicas dos compósitos } & \multicolumn{3}{c}{ Tratamentos } \\
\cline { 2 - 3 } & Pinus elliottii & Hovenia dulcis & Maclura tinctoria \\
\hline Módulo de ruptura (MPa) & $16,24 \mathrm{a}(4,55)$ & $14,03 \mathrm{a}(4,96)$ & $16,85 \mathrm{a}(3,82)$ \\
Módulo de elasticidade (MPa) & $1.390,87 \mathrm{a}(15,01)$ & $2.042,52 \mathrm{a}(12,93)$ & $1.685,76 \mathrm{a}(12,57)$ \\
Arrancamento do parafuso (N) & $710,98 \mathrm{ab}(5,54)$ & $875,24 \mathrm{a}(6,36)$ & $541,81 \mathrm{~b}(6,57)$ \\
Resistência à tração (MPa) & $0,23 \mathrm{a}(3,32)$ & $0,17 \mathrm{a}(3,25)$ & $0,22 \mathrm{a}(4,91)$ \\
\hline
\end{tabular}

*Médias seguidas pela mesma letra, na linha, não diferem entre si pelo teste de Duncan a 5\% de probabilidade. Coeficiente de variação apresentado entre parênteses (\%).

\section{Microscopia de varredura}

Nas fotomicrografias dos compósitos em estudo (Figura 1) percebe-se uma interface bem definida entre as partículas de maravalha e a matriz polimérica (Figura 1a). Além disso, pode-se observar que o derretimento do polietileno durante o aquecimento em prensa forma uma superfície regular em relação às partículas de madeira. As fibras encontram-se descoladas da matriz de poliestireno, possivelmente pelas chapas terem sido confeccionadas em camadas. As fotomicrografias ainda revelam poucos espaços vazios entre partícula e matriz termoplástica, indicando homogeneidade dos compósitos, e que a interação de poliestireno e partículas foi semelhante, independente da espécie utilizada.
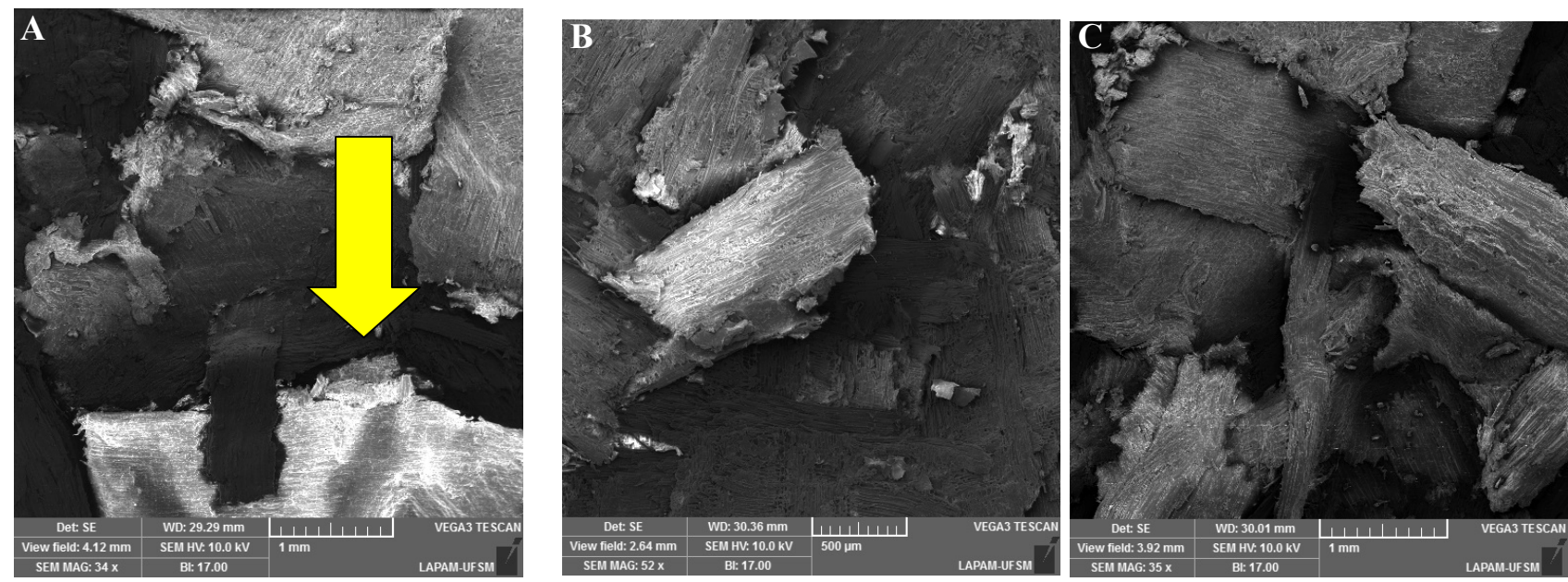

Figura 1. Detalhe da interação matriz termoplástica e serragem (CMP), confeccionada a partir de poliestireno e serragem de (A) Pinus elliottii; (B) Houvenia dulcis; e (C) Maclura tinctoria. 


\section{Discussão}

\section{Geometria das partículas}

A discrepância nos valores da relação de esbeltez disponíveis na literatura para compósitos de partículas de madeira e o presente trabalho pode ser atribuída ao uso de diferentes espécies, tipos de equipamentos para geração de partículas, espessura desejada e compatibilidade com o produto final.

Cabral et al. (2017), na confecção de painéis de pinus e de fibra de sisal verificaram o índice de esbeltez (Iez) médio por espécie de 1,5 e 53,3, respectivamente. O valor da maravalha de pinus encontra-se abaixo dos valores médios de maravalha das espécies do presente estudo (Tabela 1). Possivelmente, este fato deve-se ao equipamento do qual as maravalhas foram obtidas. A superioridade do Iez do sisal é devido às características das partículas, sendo as de serragem são arredondas e as de sisal estreitas e compridas.

\section{Propriedade físicas}

Os valores de densidade dos compósitos são maiores que os verificados por Longo et al. (2015) em painéis particulados a partir de resíduos de cinco espécies tropicais utilizando resina ureia formaldeído. Ainda, a NBR 14810 (Associação Brasileira de Normas Técnicas, 2013) propõe que a massa específica média para painéis de madeira aglomerada varie na faixa de $0,55 \mathrm{~g} \mathrm{~m}^{-3}$ a $0,75 \mathrm{~g} \mathrm{~m}^{-3}$ para painéis classificados como de média densidade, e acima de 0,75 para aqueles classificados como de alta densidade, de acordo com a norma ANSI/A 208.1 (American National Standards Institute, 2009). Desta forma, pode-se afirmar que todos os compósitos confeccionados atenderam aos requisitos normativos quanto à densidade, uma importante característica que influencia as demais propriedades dos compósitos. Adicionalmente, Rahman et al. (2013) salientam que o indicador mais importante do desempenho de um composto é a densidade, a qual afeta todas as demais propriedades dos compósitos.

Os valores de umidade dos compósitos estão abaixo do intervalo proposto pela norma brasileira NBR 14810 (Associação Brasileira de Normas Técnicas, 2013), entre $5 \%$ a $11 \%$.

Todos os painéis confeccionados apresentaram valores de inchamento em espessura após $24 \mathrm{~h}$ de imersão inferiores ao valor máximo $(35 \%)$ estipulado pela
Norma Comercial Americana CS-236-66 (Commercial Standard, 1968). Isso indica que os compósitos madeiraplástico (CMP) possuem boa estabilidade dimensional frente a situações de umidade. Além disso, outra hipótese que pode ser adicionada na discussão desses resultados físicos tem relação com o caráter hidrofóbico do plástico.

De acordo com Clemons (2002), a madeira é um material poroso, hidrofílico, que consiste de celulose, lignina e hemicelulose, que são ricos em grupos funcionais, tais como grupos hidroxilas, que prontamente interagem com moléculas de água por ligação de hidrogênio. Sendo assim, os CPM têm potencialidade de absorver água em condições úmidas. Por outro lado, materiais termoplásticos possuem caráter hidrofóbico. Portanto, a adição de materiais termoplásticos aos compósitos confere aos painéis maior resistência à absorção de água. Porém, as normas comumente utilizadas para referenciar qualidade de painéis aglomerados, como a NBR 14810 (Associação Brasileira de Normas Técnicas, 2013) e ANSI/A 208.1 (American National Standards Institute, 2009) não estabelecem referência para a propriedade física de absorção de água para esse tipo de painel.

\section{Propriedades mecânicas}

Valores semelhantes de módulo de ruptura (MOR) verificados no presente estudo foram reportados por Rahman et al. (2013) em CPMs fabricados a partir de diferentes proporções de madeira e polietileno tereftalato (PET), nas proporções de 40 e 30\% de partículas de madeira (painéis de média densidade). Ainda, os valores aferidos foram superiores ao proposto pela norma ANSI/ A 208.1-2009 (American National Standards Institute, 2009) para aglomerados de média densidade (12,8 MPa).

Contudo, todos os tratamentos apresentaram valores de comercialização requeridos pelo documento normativo ANSI A 208.1 (American National Standards Institute, 2009), sendo 1.943,8 MPa para MOR e $2.300 \mathrm{MPa}$ para o módulo de elasticidade (MOE), respectivamente, sinalizando que a maravalha pode ser utilizada na confecção de painéis.

Compósitos confeccionados a partir de materiais de baixa densidade conferem às chapas melhor desempenho quanto às propriedades mecânicas. Sendo assim, poder-se-á utilizar na confecção de compósitos uma combinação de espécies com menores massas específicas, em relação às tradicionais, em conjunto com espécies já difundidas no meio florestal, para que haja no painel maior desempenho mecânico desses compósitos. 
A resistência ao arrancamento de parafuso na face do compósito foi inferior ao mínimo estipulado pela norma ANSI/A 208.1 (American National Standards Institute, 2009), que exige, em chapas de média densidade, um valor de resistência igual ou superior a 900 N. Observou-se influência da espécie de madeira na propriedade resistência ao arrancamento do parafuso (Tabela 3), sendo que a madeira de Houvenia dulcis apresentou maior resistência. Estes resultados podem estar ligados à densidade a granel das madeiras, uma vez que a maravalha de $H$. dulcis é a que apresenta menor densidade. Eleotério (2000) ressalta que, geralmente, materiais com menores densidades permitem a fabricação de painéis com melhores propriedades mecânicas, quando comparado com aqueles que utilizam densidades superiores. Isto pode ocorrer devido à maior compactação no momento da confecção dos compósitos, o que aumenta o contato entre as partículas e possibilita uma melhor colagem. Além disso, ainda segundo o mesmo autor, espécies de baixa densidade permitem a compactação com menor demanda de pressão.

Os compósitos não atenderam aos requisitos das normas de comercialização NBR 14810 (Associação Brasileira de Normas Técnicas, 2013), que dispõe um valor mínimo de 0,35 MPa para ligação interna. Mendes et al. (2010) verificaram valores semelhantes a este estudo $(0,19 \mathrm{MPa})$, para resistência à tração, em painéis produzidos com bagaço de cana utilizando como adesivo ureia-formaldeído.

\section{Microscopia de varredura}

Para Melo \& Del Menezzi (2010) a absorção de água nos painéis de partículas ocorre através dos espaços vazios presentes no interior do material. Sendo assim, as imagens (Figura 1) possibilitam explicar a baixa absorção de água e inchamento em espessura dos tratamentos em estudo. Possivelmente, os poucos espaços vazios verificados explicam a pouca diferenciação de comportamento nos ensaios físicos e mecânicos dos compósitos confeccionados neste experimento.

\section{Conclusão}

Os compósitos apresentaram homogeneidade nos resultados, indicando que a espécie utilizada pouco interferiu nos ensaios.

De maneira geral, os compósitos madeira-plástico (CMP) apresentaram boa qualidade, atendendo as normativas técnicas quanto à densidade e nos ensaios de módulos de ruptura e elasticidade e inchamento em $2 \mathrm{~h}$ e $24 \mathrm{~h}$. Acredita-se que os bons resultados sejam devido à adição de poliestireno. No entanto, os CMP não apresentaram resultados satisfatórios nos ensaios de ligação interna e arrancamento do parafuso.

\section{Referências}

American National Standards Institute. ANSI A208.1: matformed wood particleboard: specification. Gaithersburg: National Particleboards Association, 2009.

American Society for Testing Materials. ASTM D-1037: standard methods of evaluating the properties of wood-base fiber and particle materials, 1993.

Anuário estatístico ABRAF 2013: ano base 2012. Brasília, DF: ABRAF, 2013.

Associação Brasileira de Normas Técnicas. NBR 14810: painéis de madeira de média densidade. Rio de Janeiro, 2013.

Cabral, M. R. et al. Painéis de partículas com maravalha de Pinus spp. e fibra de sisal. Scientia Forestalis, v. 45, n. 114, p. 353-362, 2017. DOI: $10.18671 /$ scifor.v45n114.11.

Commercial Standard. CS 236:66: mat formed wood particleboard. [Washington], 1968.

Clemons, C. Wood-plastic composites in the United States: the interfacing of two industries. Forest Products Journal, v. 52, n. 6, p. 10-18, 2002.

Correa, C. A. et al. Compósitos termoplásticos com madeira. Polímeros: Ciência e Tecnologia, v. 13, n. 3, p. 154-165, 2003. DOI: 10.1590/S0104-14282003000300005.

Eleotério, J. R. et al. Propriedades físicas e mecânicas de painéis MDF de diferentes densidades e teores de resina. Ciência Florestal, v. 10, n. 2, p. 75-90, 2000. DOI: 10.5902/19805098482.

Longo, B. L. et al. Caracterização tecnológica de peinéis particulados produzidos con residuos de cinco espécies tropicais. Scientia Florestalis, v. 43, n. 108, p. 907-917, 2015. DOI: 10.18671/scifor. v43n108.15.

Maciel, A. S. et al. Painéis de partículas aglomeradas de madeira de Pinus elliottii Engelm., poliestireno (PS) e polietileno tereftalato (PET). Revista Árvore, v. 28, n. 2, p. 257-266, 2004. DOI: 10.1590/ S0100-67622004000200012.

Melo, R. R. \& Del Menezzi, C. Influência da massa específica nas propriedades físico-mecânicas de painéis aglomerados. Silva Lusitana, v. 18, n. 1, p. 59-73, 2010.

Mendes, R. F. et al. Associação de eucalipto e pinus na produção de painéis aglomerados de bagaço de cana. In: ENCONTRO BRASILEIRO EM MADEIRAS E EM ESTRUTURAS DE MADEIRA, 12., 2010, Lavras. Madeira para todos: os desafios: anais. Lavras: UFLA, 2010.

Rahman, K. S. et al. Flat-pressed wood plastic composites from sawdust and recycled polyethylene terephthalate (PET): physical and mechanical properties. Springer Onpen, n. 2, p. 629, 2013. DOI: 10.1186/2193-1801-2-629. 
Yamaji, F. M. \& Bonduelle, A. Utilização da serragem na produção de compósitos plástico-madeira. Floresta, v. 34, n. 1, p. 59-66, 2004. 
